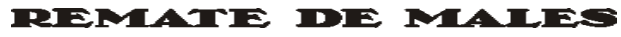

Campinas-SP, v. 38, n. 1, pp. 398-413, jan./jun. 2018

\title{
LITERATURA COMO ANTROPOFAGIA EM Silviano SANTIAgo: ANOTAÇões SObRe UM PERCURSO FICCIONAL ATÉ O ROMANCE MACHADO
}

\author{
Ângela Maria Dias ${ }^{1}$
}

\begin{abstract}
Resumo: O presente texto pretende desenvolver uma reflexão sobre o romance mais recente de Silviano Santiago: Machado (2016b). Já estudado por suas incursões pela ficcionalização de Graciliano Ramos depois do cárcere, no Em liberdade (1981), e da viagem de Antonin Artaud ao México, no Viagem ao México (1995), o escritor agora aventura-se na celebração do universo de Machado de Assis. A narrativa de 2016, ao perfazer uma mistura entre romance, ensaio, biografia e crítica de costumes, dedica-se a retomar os últimos anos do mais aclamado romancista da literatura brasileira, em seu ocaso de melancólica viuvez e crises nervosas. A abordagem se propõe a enlaçar a perspectiva da assinatura como identidade móvel e em constante processo de mutação com o legado da antropofagia, em que a apropriação criativa da contribuição do outro celebra um horizonte compartilhado como ponto de fuga.
\end{abstract}

Palavras-chave: antropofagia; apropriação; alteridade.

Borges (1986, p. 108), num belo artigo sobre Flaubert, celebra-o como "o primeiro Adão de uma nova espécie: a do homem de letras como sacerdote, asceta e quase como mártir". Conforme nos recorda Leyla Perrone-Moisés (2016), Barthes, em 1980, em seu último curso no Collège de France retoma, com melancolia, o entusiasmo do escritor argentino quando comenta o "desaparecimento dos líderes literários", que ele, ao fazer eco a Baudelaire, denomina de "heróis": "É essa Figura - ou essa

1 Ângela Maria Dias professora titular de Literatura Comparada da UFF, do Departamento de Letras Clássicas e Vernáculas e do Programa de Pós-Graduação em Estudos de Literatura: angelmdias@gmail.com. 
Força - do Herói literário que perde hoje sua vitalidade" (BARTHES, 2005, pp. 312-313).

Numa entrevista à Folha de São Paulo no dia 13 de dezembro de 2016, Silviano Santigo considera o seu último e recém-publicado romance como "um legado à literatura brasileira e, em especial, à sua figura maior, que é Machado" ([s.p.]).

Perrone-Moisés (2016, p. 125), ao deter-se sobre os romances construídos em torno de grandes figuras literárias, comenta que eles constituem "um subgênero romanesco que tem crescido visivelmente desde os anos 1980" e atribui a sua notoriedade atual a causas, como o individualismo contemporâneo e a ausência de padrões éticos estáveis. Entretanto, a crítica aponta que esse tipo de celebração a figuras e personalidades de singular talento configura pontos de fuga exemplares, objetos de desejo, cuja distância pode ser estimulante.

Essa presença do passado no âmago da construção do presente já tinha sido pensada por Lyotard (1987, pp. 24-26) a propósito da condição pós-moderna. Quando lhe atribui a busca de novas presentificações "para melhor fazer sentir o que há de impresentificável”, o filósofo já pensa a pós-modernidade também entre o remorso do que não é mais e o ensaio daquilo que ainda não é.

A busca de novas possibilidades e categorias, no intuito de estabelecer as regras daquilo se que faz, talvez explique a práxis de grande parte da produção artística da modernidade tardia, entendida, ainda de acordo com o pensador, como movida "segundo o paradoxo do futuro" (LYOTARD, 1987, p. 25), ou seja, por uma dinâmica em que o "pós" tenta recapturar o "anterior" para dele se alimentar e produzir o que ainda não sabe.

Assim, a injunção contemporânea, ao situar-se na arqueologia da modernidade, passa a reconhecer-se, como a justificou o teórico francês, na sua qualidade de elaboração da ruptura moderna, de "anamnese" de seu "esquecimento inicial" (LYOTARD, 1987, p. 98) do passado. Isso porque o objetivo ou o ponto de fuga de toda presentificação é sempre o impresentificável. Desse modo, a temporalidade do contemporâneo, expandida por sua tendência a atualizar o passado, recria, pelo presente domínio da tecnociência, os índices desse passado.

Nesse sentido, teóricos como Severo Sarduy (1979) e Omar Calabrese (1989) detectam a inscrição de traços materiais do Barroco no seio do presente. Semelhante "lógica da cultura" nos seiscentos permite "conexões improváveis” entre o pensamento científico e a forma dos fenômenos 
culturais. Assim, a doutrina copernicana de que a Terra gira ao redor do Sol tira a centralidade do homem e atribui ao universo a infinitude unitária de uma máquina ideal alimentada por um sistema de mútuas influências. Em resposta a isso, desenvolve-se na filosofia, com a dissolução do transcendentalismo medieval, o "estremecimento metafísico", a angústia de Pascal diante do "silence éternel des espaces infinis" [silêncio eterno dos espaços infinitos], o assombro diante do largo e incessante alento que penetra o todo (HAUSER, 1969, p. 108).

Da mesma maneira, na atualidade tal tipo de parentesco ocorre, segundo Calabrese (1987, pp. 10 e 19), quando podemos vincular as teorias do caos e da complexidade a certas formas da arte, da literatura e da filosofia. Se o século XVII experimenta uma crise epistemológica que indica a mudança de paradigmas e traduz tais transformações pelo topos da alegoria, em sua desolada alusão à ruína e à morte, também nossa época vive uma profunda ruptura epistêmica e as incertezas dela decorrentes, em virtude do surgimento de novas configurações do espaço e do tempo.

A esse respeito, teóricos como Gumbrecht (2015) e Harvey (2014) postulam que o cronótopo do pensamento histórico se manteve vigente, na regulação das perspectivas individuais e das relações sociais, desde o início do século XIX até o final da Segunda Grande Guerra, sendo, depois disso, gradativamente substituído em função de transformações econômicas, sociais e científico-tecnológicas.

O novo cronótopo, ainda sem nome, em vigor a partir do final dos anos de 196o, investe a nossa contemporaneidade com o que Gumbrecht (2015, p. 141) denomina de presente expandido e prevalente. Em seu protagonismo, esse presente se deixa invadir pelo passado e esgota o futuro pela repetição de presentes heterogêneos que, desvinculados de qualquer causalidade, passam a suceder-se, numa alternância de instantes equivalentes e simultâneos.

Quanto mais distantes as velhas certezas inerentes ao fluxo temporal da consciência histórica, já que o futuro deixa de ser horizonte de possibilidades e o passado se transforma em fantasmagoria tecnológica, mais demandamos por "momentos de presença no nosso amplo presente" (GUMBRECHT, 2015, p. 141) desrealizado.

Esse estado de coisas certamente pode justificar a proliferação de um tipo de literatura melancólica voltada para elaborar o luto da ausência das grandes lideranças espirituais e artísticas na atualidade. Trata-se da 
narrativa ficcional da vida de marcantes autores e criadores da tradição, revisitados pelos escritores contemporâneos na busca de resgatar seus méritos e sua exemplaridade.

O peso da tradição na contemporaneidade passa então a gerar uma profusa galeria de espectros, cuja invocação pode ser emuladora no que promove o trabalho da herança. Em Espectros de Marx, Jacques Derrida (1994) desenvolve uma alentada reflexão sobre o tema, partindo da memorável expressão do filósofo para designar o comunismo como "um espectro" que "ronda a Europa".

A espectrologia derridiana - termo resultante de um trocadilho em francês, formado pela palavra "hantologie", como neologismo criado com o verbo "hanter" (assombrar) e a palavra "ontologie", impraticável, portanto, em português - volta-se para o questionamento do que caracteriza como "a heterogeneidade radical e necessária de uma herança” (DERRIDA, 1994, p. 33), ou seja, sua injunção híbrida, que exige do herdeiro uma escolha entre vários possíveis. Nesse sentido, a diretriz crítica decorre forçosamente da interpretação, na medida em que herdamos sempre "um segredo" que nos interpela, para que possamos reafirmar a herança e reafirmar-nos por ela (DERRIDA, 1994, p. 33).

Tal exigência tem a ver com a condição de finitude do homem, com a sua experiência de um presente deslocado e anacrônico, "na junção de um tempo radicalmente dis-junto", que afinal, é o que possibilita "a dissimetria infinita da relação com o outro" (DERRIDA, 1994, pp. 34-40).

Essa heterogeneidade é justamente o que instaura a oportunidade do porvir a partir de um passado. Por isso, Derrida (1994, p. 57) sugere que "o porvir não pode ser senão dos fantasmas. Assim como o passado”. Ainda por isso, o filósofo duvida "da contemporaneidade a si do presente", já que "o presente se passa [...] no vai e vem, entre o que vai e o que vem" (p. 43).

Assim podemos enlaçar as premissas da espectrologia derridiana sobre o anacronismo do presente com a reflexão de Lyotard, esboçada anteriormente, sobre a encruzilhada da modernidade tardia entre o remorso e o ensaio. De fato, não é difícil de constatar o quanto a nossa contemporaneidade é propícia ao espectral, como refém de imagens e dispositivos, em que o teatro da técnica desperta todos os mortos e multiplica os fantasmas. Nesse sentido, a sociedade do espetáculo, em seu cosmopolitismo hedonista, ao operar o paradigma tecnológico, anima o circuito da mercadoria com uma bricolagem entre espectros e 
fantasmagorias, que, em sua disjunção temporal, contagia o devir das formas de nosso tempo de tensão e paroxismo.

Na contemporaneidade hipermidiática e inflacionada de dispositivos tecnovisuais, o Theatrum Mundi barroco é uma constante inarredável. Assim o intercâmbio entre os diferentes códigos artísticos, desencadeado pelas vanguardas do início do século XX, hoje se acirra em proporções sempre mais intensas e assíduas. Daí que a teatralidade, ao constituir a potencialidade cênica de um discurso, pode ser surpreendida em todas as formas de criação.

Essa transversalidade do teatral nas manifestações artísticas tem a ver também com a urgência da presentificação, ou com a nostalgia da presença já aludida na sintomatologia da época. De fato, o esforço na elaboração da herança constitui a possibilidade de ultrapassagem da melancolia no encalço da superação do luto. Talvez por isso a polifonia do atual inclua com tanta assiduidade as figuras engenhosas da paródia e do pastiche, e todo um cortejo de experimentalismos voltados para o exorcismo da dívida frente ao peso monumental da tradição.

No que tange particularmente à cultura brasileira, a travessia da condição colonizada gera, na trajetória da autonomização, em plena eclosão da modernidade, a antropofagia como estratégia e modo de processamento da herança. Embora já se tenha argumentado que "a presença de um veio antropofágico e carnavalizante na cultura e na literatura brasileira não é uma propriedade exclusiva da obra de Oswald de Andrade" (HELENA, 1983, pp. 91-92), acreditamos que é justamente por meio de suas indicações que a antropofagia surge como "uma definição metafórica da apropriação da alteridade” (ROCHA, 2011, p. 662). Ou seja, a partir daí, ocorre de forma consciente o exorcismo crítico da autoridade cultural que durante tantos anos nos submeteu. Nesse sentido, o seu emblema se constitui "fonte de importante contribuição à desconstrução do pensamento identitário ocidental" (p. 662).

Por outro lado, segundo Benedito Nunes (1979), tal ímpeto renovador vai diferenciar-se de outros movimentos da vanguarda internacional como o Surrealismo, o Dadaísmo, o Futurismo - no que se recusa a negar o passado canônico e, muito ao contrário, se propõe a dele se apropriar de maneira livre e criativa. Como fator endógeno incorporado à tradição moderna do pensamento nacional, em determinadas épocas, a força desse ímpeto reemerge. No Tropicalismo do final dos anos de 1960, a antropofagia torna-se a palavra de ordem de insubordinação da força aos parâmetros 
do nacionalismo estreito e populista então vigente, em expressiva parcela da intelectualidade artística atuante naquele momento.

Como constata Caetano Veloso (1997, p. 249), em Verdade tropical, sobre a radicalidade do movimento:

Tal como eu a vejo, ela é antes uma decisão de rigor do que uma panaceia para resolver o problema de identidade no Brasil. A poesia límpida e cortante de Oswald é, ela mesma, o oposto de um complacente "escolher o próprio coquetel de referências". A antropofagia, vista em seus termos precisos, é um modo de radicalizar a exigência de identidade (e de excelência na fatura), não um drible na questão. Nós tínhamos certeza de que João Gilberto [...] era um exemplo claro de atitude antropofágica. E queríamos agir à altura.

Também as comemorações dos quinhentos anos da descoberta do Brasil criam uma ocasião para a reemergência da antropofagia, em sua potência de incorporação e renovação. Assim, em 1998, a Bienal de São Paulo celebra "o banquete antropofágico" como "um modelo de diálogo" (HERKENHOFF, 1998, p. 23). Em diferentes períodos de nossa história, a antropofagia é invocada por sua insubordinação ao consagrado e pelo ímpeto de renovação do nosso histórico descentramento.

Entretanto, a par da possibilidade de um esboço histórico das recorrências antropófagas, conforme argumenta Rocha (2011), é produtivo pensarmos esse expediente de apropriação da alteridade no mundo atual pela premência necessária à gestão da infinidade de dados produzidos de maneira incessante pelo aparato tecnológico, e seu tratamento num regime de otimização crítico-teórica.

Nesse sentido, o seu enraizamento no contexto histórico brasileiro, resultante de séculos de colonização, poderia conduzir o pensamento da antropofagia a funcionar como via reflexiva e instrumento compensatório para ser investido em situações de desigualdade socioeconômica e/ ou político-cultural. Em nossa história literária, antes de Oswald de Andrade e seu grupo de antropófagos, já a figura de Machado de Assis pode ser reconhecida como um patrono da ideia, bastante consciente das apropriações de que se vale.

Como é bem reconhecido pela fortuna crítica machadiana, o escritor era um leitor prolífico, dono de vasta biblioteca, e sempre reconheceu a precedência da leitura na formação de um escritor. Por outro lado, como crítico atuante, Machado assiduamente manifestava um profundo respeito pelo conhecimento da tradição literária e pela importância da prática do transplante e do diálogo com os pósteros pelos escritores de seu tempo. 
Rocha (2013, p. 44) assinala, em Machado de Assis: por uma poética da emulação, a absorção pelo Machado-crítico "de uma opção estética deliberadamente anacrônica”, em que a originalidade passa pela imitação dos modelos consagrados, seguida do transplante de seu modus faciendi, para a dicção peculiar do escritor-leitor. Ou seja, segundo o crítico, a ideia de Machado sobre a originalidade artística recupera, em tempos pós-românticos, a tradição como fonte de criatividade e abre inusitada senda para a sua grande virada criativa: a revolução operada nas Memórias póstumas.

Por sua vez, o narrador-autor de Machado, Silviano Santiago (20oo, p. 25), escritor-crítico e leitor contumaz, é o teórico que consagrou o entre-lugar como o espaço privilegiado do escritor latino-americano, em seu compromisso de perverter e revirar o signo estrangeiro e "aceitar a transgressão como forma de expressão".

Talvez por isso mesmo, Silviano Santiago ficcionista, desde o início de sua obra, tenha produzido narrativas dedicadas a figurar espectros de escritores e artistas, em situações imaginadas e/ou imaginárias. Essa apropriação cênica dos "heróis da literatura”, em diversas circunstâncias, tem início no Em liberdade, de 1981, em que resolve recriar literariamente os primeiros dias do escritor Graciliano Ramos fora da prisão, a que este fora submetido na ditadura de Vargas, por razões políticas. Em seguida continua essa tendência, anos depois, em 1995, com o também romance Viagem ao México, em que reporta ficcionalmente a viagem de Antonin Artaud ao México.

O entre-lugar como emblema capaz de dar conta das sucessivas metamorfoses da persona autoral de Silviano Santiago constrói um espaço de possibilidades subversivas em que o escritor é sempre o ficcionista-leitor, em busca de novos horizontes de criação de identidades prismáticas e multifacetadas, ou do que poderia ser considerado, como uma modalidade de "assinatura informe ou monstruosa".

Assim, em 1981, com Em liberdade, buscando discutir a aspereza das relações entre intelectual e poder, Silviano se funde ao escritor Graciliano Ramos, recém-saído da detenção, em 1937, no Estado Novo, para produzir, segundo palavras suas, uma "prosa limite" voltada para a construção de um diário das vicissitudes e dificuldades do escritor, até o momento em que este produz o seu Memórias do cárcere, em 1954. Tal "transe perfeito", nas palavras de Caio Fernando Abreu (1981, p. 113), em um artigo publicado em Veja vai produzir, segundo as palavras do próprio autor de Machado, 
um "resultado tripartido: o fingimento na biografia, o factual na ficção, o sujeito na teoria crítica” (SANTIAGO, 1992, p. 85).

Já em 1995, com Viagem ao México, o diálogo contrapõe Silviano a Artaud, na incursão deste ao país em 1936, em busca de motivos para a desconstrução do convencionalismo do teatro europeu, por meio da ancestralidade mítica e das raízes tradicionais da cultura mexicana, tentando despertar nesse percurso uma espécie de descolonização na América frente ao estigma da dependência cultural. Trava-se, então, uma espécie de contraponto entre o escritor brasileiro, investido no papel de transgressivo dissipador do "véu do imperialismo cultural" (SANTIAGO, 1992, p. 85), e o teatrólogo francês, em seu empenho na imersão no âmago das culturas oprimidas, pelo contato com seus sobreviventes. Nesse sentido, o livro de Silviano se configura no rastro da escrita de Os Tarahumas, mais tarde escrito por Artaud, a partir de seu convívio com a tribo.

Como se pode constatar, trata-se de uma trajetória ficcional toda construída por meio de embates entre vozes superpostas, na criação de obras concebidas na tradução/traição de outras obras e experiências criativas anteriores. Esse tipo de produção, enfaticamente metaficcional e interdiscursiva, certamente recupera a formação do escritor como crítico e, sobretudo, como ensaísta. O entre-lugar, ainda e sempre constituindo a morada de Silviano-autor, pode ser visto como o espaço de manobras inerentes à produção do ensaio como forma. E, nessa mesma linha, a antropofagia como estratégia que se apropria da alteridade pode ser entendida no seu imbricamento com o cerne da natureza do ensaio. Lukács (2015, p. 39), no seu memorável texto de 1911, "Sobre a forma e a essência do ensaio: carta a Leo Popper", considera que "toda escrita representa o mundo numa relação de destino" e, dessa maneira, enlaça radicalmente as noções de destino e de forma. Em relação ao ensaio, partindo dessa premissa, o teórico assinala, então, que "nos escritos de ensaísta, a forma se faz destino, princípio criador de destino", para, em seguida, concluir que "o crítico é aquele que enxerga o destino nas formas [...] que as formas indireta e inconscientemente abrigam em si mesmas” (pp. 39-40).

A obra ficcional de Santiago, em sua vocação erótico-crítica na deglutição traiçoeira dos mais variados repertórios artísticos e culturais, encena de modo formidável o destino de uma alma completamente movida pela sedução da leitura e da reflexão, na encruzilhada entre a tradição compartilhada e o estimulante ensaio do que ainda não se concebe. 
Recentemente, essa apropriação transfigurada de escritores célebres tem elegido Machado de Assis, que Silviano considera como o nosso maior escritor. Nesse sentido, a inauguração da linhagem machadiana pode ser encontrada no romance Heranças (SANTIAGO, 2008), quando Walter, o narrador-personagem do romance, adota uma dicção de ironia provocativa para narrar desinibidamente a própria vida, numa espécie de atualização da voz desafiadora do inconfundível escritor-defunto Brás Cubas.

Santiago, ao valer-se da ideia da obra de Machado, como abertura para outros caminhos, hipertrofia o seu tom e o satura de derrisão no apelo ao pastiche. Assim, a ironia machadiana, nesse novo contexto, converte-se em teatro, num constante malabarismo metamórfico em que os procedimentos narrativos do autor de Dom Casmurro são constantemente transgredidos e abusados. Nessa progressão metaficcional, o pastiche transforma o estilo digressivo do mestre numa caleidoscópica sucessão de provocações levianas; sua ironia, num deslavado cinismo; os cortes no fluxo narrativo, em subterfúgios maliciosos e válvulas de escape ao confessionalismo. Tudo isso aliado à contramoldagem assídua do arsenal alegórico de Machado, em sua concisão coloquial e alusividade ética, pela via do rebaixamento neonaturalista e prosaico.

Já Machado, também romance, publicado em 2016, retoma a linha da criação espectral numa chave estruturalmente bem profusa, embora assimilando de maneira frontal a biografia do grande escritor, sem deixar de combiná-la a muitos outros registros e gêneros ficcionais e não ficcionais. Trata-se de uma catedral de mosaicos cuja confecção será desencadeada, numa manhã de junho de 2015, conforme confessa o poderoso narrador-autor, pela compra do quinto volume da correspondência de Machado de Assis, entre 1905 e 1908, trocada nos derradeiros anos de vida do escritor.

Só essa circunstância já caracteriza o relato como escrita do eu, na medida em que o leitor, constantemente interpelado na narração, fica imediatamente informado sobre a motivação da escolha criativa, baseada numa tendência bastante íntima do narrador-autor que, inclusive, a aponta como responsável pelas outras bioficções já referidas que publicou, respectivamente em 1981 e 1995. Assim, na segunda página da narrativa (SANTIAGO, 2016b, p. 14), lê-se: "Aprecio a curta fração do tempo. Fascina-me enxergar a graça e o valor da experiência humana pela abreviação de longo e extraordinário percurso individual em pouquíssimos anos salientes". 
O rastro da correspondência, citada em diversos momentos do relato, não só oferece o fio pelo qual o narrador-autor dá conta dos últimos anos do criador célebre - descendo a minúcias documentais e biográficas - como também propicia o mote a ser glosado pelas tintas da invenção ficcional.

Essa via de reescrita do passado, tornando o escritor célebre contemporâneo ao narrador-autor, como "compagnons de route" (SANTIAGO, 2016b, p. 51), opera o seu deslocamento e vai transformá-lo em pura sincronia, colocando-o no âmago do contemporâneo como presente expandido.

A correspondência, aliada a uma infinidade de outros livros e documentos, vai construir um leito profícuo de pesquisa tanto dos anos finais do escritor, quanto da ruína do Rio de Janeiro imperial, sob a administração do prefeito Pereira Passos, em seu projeto de fazer surgir, de um monte de escombros de ruelas, becos e prédios antigos deteriorados, uma cidade moderna, digna do século XX.

Dessa forma, o autor-narrador, ao reunir uma impressionante coleção de materiais híbridos - como cartões-postais, notícias de jornal, charges, fotografias, letras de marchinhas populares, extratos de artigos técnicos sobre medicina e saúde e o que mais - na verdade está compondo um quebra-cabeça, uma colcha de retalhos, uma impressionante bricolagem de materiais radicalmente alegóricos, no sentido de performatizar o "lento desaparecimento" (SANTIAGO, 2016b, p. 77) do homem célebre e a transformação da cidade ao seu redor.

Assim, o gosto da citação, incorporada das mais diversas maneiras, tem a ver com o "puro amor da escrita", o gosto pela fabulação que, por sua vez, relativiza a diferença entre a recolha documental e a invenção (SANTIAGO, 1989, p. 191).

Trata-se, antes de tudo, de uma escrita por imagens, tal como interpretada por Benjamin (1984, p. 207), na Origem do drama barroco alemão, quando a caracteriza como "o desnudamento das coisas sensoriais" num contexto de desdobramento da imagem que se explica pelo emblemático:

O emblemático não mostra a essência "atrás da imagem”. Ele traz essa essência para a própria imagem, apresentando-a como escrita, como legenda explicativa, que nos livros emblemáticos é parte integrante da imagem representada. (BENJAMIN, 1984, p. 207) 
Nessa linha de compreensão, as associações livres de Santiago-narrador configuram um patchwork que, na verdade constitui o modo de produção desse romance múltiplo, simultaneamente biografia, ficção, ensaio, crônica histórica, crítica literária e diário íntimo. Tudo isso, em ritmo de performance, ou seja, oferecendo-se como reescritura cênica de vetores textuais e teatrais, basicamente centrados no corpo do autor que reescreve a progressão das mortes, ao mesmo tempo que acompanha o próprio processo de envelhecimento.

Assim, o entrelaçamento de nós temáticos e a extrema visualidade integram uma escrita intermitente e descontínua, em ininterrupto movimento no qual a estrutura fragmentária tende a estender-se indefinidamente.

Essa obsessiva busca por capturar a gradação destrutiva inerente à finitude talvez constitua o alimento maior do jogo de espelhos encenado na narrativa. Assim, se cruzam e se correspondem o envelhecimento do corpo do autor-narrador, o desaparecimento dos "filhos da cidade", ou os últimos anos da vida "do escritor viúvo", e o processo de rejuvenescimento do Rio de Janeiro, a partir de 1904, ou o que também é referido como o "fracasso da velha imperial cidade colonial" (SANTIAGO, 2016b, p. 77).

Tal apego virtuosístico ao ritmo e ao policentrismo é sintoma de uma preferência do narrador-autor pelas figuras do gosto barroco: o jogo de espelhos e reflexos, e seus efeitos de duplicação; o labirinto, no qual as formas se sucedem em inusitadas combinações; e a metamorfose, que processa a multiplicidade de imagens, emblemas e de alusões diversificadas.

O vínculo entre o talento literário do escritor exemplar e sua doença é alegorizado no romance pelo emblema que Santiago (2016b, p. 24) denomina de "musa convulsiva". Assim, "a beleza convulsiva" na obra de Machado recupera imageticamente o "eixo enviesado de sustentação da epilepsia” (p. 236) a que responde "a proposta artística machadiana, convulsiva por natureza”, em seu estranhamento diante dos tempos e modos da sua época, pautados "em princípios retóricos orientados pela simetria perfeita” (p. 216) e pela reverência exibicionista ao solene e ao consagrado.

A sutileza e a variedade dos enlaces desfiados pela engenhosidade do narrador-autor, ao simular a consagrada volubilidade do narrador machadiano, fazem desfilar aos olhos do leitor um caleidoscópio de 
quadros e imagens sucessivos, a partir da eleição de motivos díspares, eleitos por uma relação de simpatia.

A palavra, grávida de imagens e ancorada no corpo, perfaz uma proliferação incessante de cenas, ideias e emblemas, num exercício intertextual alimentado pela figura tutelar do escritor maior. Essa eleição e essa apropriação mágicas, segundo a explica o narrador-autor, resultam do "jogo de dados do Acaso", capaz de sobrepor o dia e mês do seu nascimento, em 1936, ao "dia e mês em que morre o grande escritor em 1908, 29 de setembro" (SANTIAGO, 2016b, p. 52).

A aludida "reencarnação" do célebre espectro "na pele" do "diferente e ousado personagem" Silviano Santiago, "a sobreposição e o acoplamento das duas vidas afins e distintas" (SANTIAGO, 2016b, p. 53), funcionam como uma apropriação antropofágica do legado de Machado de Assis pelo escritor, crítico e malabarista gourmet, autor de Machado.

Assim, o espelhamento se distende e multiplica em proporções, à primeira vista, não consideradas. Já no segundo capítulo, o narrador-autor invoca o deus Jano, na figuração de um símbolo emblemático da dívida, o espectro, como herança seletiva: "A escapada do passado em direção ao futuro, ou a viagem do futuro em busca do passado, transfigurará aos dois na cara duma moeda única chamada Literatura. Duas caras, uma só coroa" (SANTIAGO, 2016b, p. 57).

A tutela do espectro, que começa pelo aprendizado dos elementos trademark do seu estilo - "corte, abertura, digressão, safanão estilístico e tranco narrativo” (SANTIAGO, 2016b, p. 281) -, inicia-se bem antes pelo modo de produção machadiano.

Nesse sentido, os roteiros adotados pelo crítico Silviano Santiago (2008b) no artigo "O começo do fim", poderiam servir de indicação para compreendermos a construção heterodoxa de associações, encaixes e analogias que produzem o romance Machado.

A abordagem da doutrina antropófaga como contraditória combinação entre a teoria poética de Paul Valéry, o Futurismo e o Anarquismo Dada, ao desdobrar-se na indicação do seu vínculo com o construtivismo brasileiro dos anos 1940 e 1950, revela justamente, no âmago do banquete antropófago, a opção pela busca da verdade poética como esforço do artifício contra os romantismos da inspiração.

Não é por outro motivo que o crítico, no mesmo artigo, é levado ainda a constatar sobre o assunto: 
Ela exige do artista, cuja tradição cultural se encontra em princípio desapossada do ideal de universalidade criado pela tradição ocidental, o gosto pelo trabalho artístico que não é desassociado do trabalho crítico, também de responsabilidade do próprio criador (SANTIAGO, 2008b, p. 18).

Nessa linha, Santiago assinala, no desafio antropófago ao universalismo da cultura europeia, a sua clara rejeição da dívida do não europeu com o legado do saber metropolitano e a consequente aposta ética na devoração da memória universal, em sua diversidade, como comunhão.

Nada mais congenial ao método de produção de Machado, romance que poderia ser visto também, em virtude dos enlaces que apresenta, como um palimpsesto, em que os signos desenhados são rasurados sem cessar em favor de outros, numa dinâmica de crescente volubilidade. Aliás, não é por acaso que uma das epígrafes do livro seja uma comparação de Thomas De Quincey entre o cérebro humano e o palimpsesto, e a outra, uma consideração de Sartre a respeito de seu livro sobre Flaubert, como ficção tecida "por meio de hipóteses".

Esse prolífico entrelaçamento de cacos ficcionais, causos, emblemas e divagações, de inegável vocação antropófaga, na absorção indiscriminada do alto e do baixo, em permanente deslocamento inventivo, talvez possa ser compreendido como um modo de produção romanesco aparentado à rapsódia. Não apenas pela recolha que realiza de fragmentos narrativos desiguais e de um volume de dados considerável, em sua disparidade, mas também na acepção para esse termo do dicionário Houaiss (2009), que também o define como peça musical de forma livre que mistura melodias, processos de composição improvisada e efeitos instrumentais de determinadas músicas nacionais ou regionais.

Nessa deriva rapsódica, o capítulo que encerra o livro, intitulado “Transfiguração", certamente constitui o ponto alto da costura combinada de fragmentos, histórias e peças da mais diversa procedência. A barroca encenação desse último episódio, na verdade, é anunciada na primeira página do romance, com a reprodução da tela Transfiguração, de Rafael, que apresenta a cura de um epiléptico pelo Cristo transfigurado, diante de alguns apóstolos e de uma pequena plateia. O estigma da doença, tratado durante todo o romance e aqui, nesse gran finale, retomado com pompa, talvez codifique o emblema-síntese desse profuso bordado: a imaginação poética como torção do consagrado e a criação entendida como transfiguração do corpo na obra. 
Remate de Males, Campinas-SP, v. 38, n. 1, pp. 398-413, jan./jun. 2018 - 411

\title{
LITERATURE AS ANTROPOFAGIA IN SILVIANO SANTIAGO: NOTES ON A FICTIONAL PATH UNTIL THE NOVEL MACHADO
}

\begin{abstract}
This text aims to develop a reflection about the most recent novel by Silviano Santiago: Machado (2016b). Almost known by fictionalized incursions of Graciliano Ramos' life after prision, in Em liberdade (1981), and as well over the Antonin Artaud' trip to Mexico, in Viagem ao México (1995), the writer now dares to celebrate the universe of Machado de Assis. The narrative of 2016, consisted by a mixture among novel, essay, biography and social criticism, intends to recall the latest years of the most acclaimed writer of Brazilian literature, in their decline of melancholic widowhood and nervous crisis. The approach proposes to link the perspective of signature as a moving identity in a constant process of mutation, and the heritage of "antropofagia". This legate, as has been historically discussed, celebrates the creative appropriation of the other as a utopian search.
\end{abstract}

Keywords: antropofagia; appropriation; otherness.

\section{REFERÊNCIAS}

ABREU, Caio Fernando. Transe perfeito. Veja, São Paulo, 23 set. 1981, pp. 113-114.

BARTHES, Roland. A preparação do romance II: a obra como vontade: notas do curso no Collège de France 1979-1980. Texto estabelecido e anotado por Nathalie Léger; trad. Leyla Perrone-Moisés. São Paulo: Martins Fontes, 2005 (Coleção Roland Barthes)

BENJAMIN, Walter. Origem do drama barroco alemão. Trad. Sergio Paulo Rouanet. São Paulo: Brasiliense, 1984 .

BORGES, Jorge Luis. Discussão. Trad. Cláudio Fornari. São Paulo: Difel, 1986.

CALABRESE, Omar. A idade neo-barroca. São Paulo: Martins Fontes, 1989.

DERRIDA, Jacques. Espectros de Marx: o estado da dívida, o trabalho do luto e a nova Internacional. Trad. Anamaria Skinner. Rio de Janeiro: Relume Dumará, 1994.

GUMBRECHT, Hans Ulrich. Nosso amplo presente: o tempo e a cultura contemporânea. Trad. Ana Isabel Soares. São Paulo: Editora Unesp, 2015.

HARVEY, David. Condição pós-moderna: uma pesquisa sobre as origens da mudança cultural. 25. ed. Trad. Adail Ubirajara Sobral e Maria Stela Gonçalves. São Paulo: Edições Loyola, 2014 .

HAUSER, Arnold. Historia social de la literatura y el arte. V II. Trad. A. Tovar e F. P. VarasReyes. Madrid: Ediciones Guadarrama, 1969.

HELENA, Lúcia. Uma literatura antropofágica. 2. ed. Fortaleza: Universidade Federal do Ceará, 1983. 
HERKENHOFF, Paulo. Catálogo da XXIV Bienal de São Paulo. In: Núcleo Histórico: antropofagia e histórias da civilização. São Paulo: Fundação Bienal de São Paulo, 1998, [s.p.].

HOUAISS. Dicionário eletrônico Houaiss da língua portuguesa. Rio de Janeiro: Objetiva, 2009.

LYOTARD, Jean-François. O pós-moderno explicado às crianças. Trad. Tereza Coelho. Lisboa: Publicações Dom Quixote, 1987.

LUKÁCS, Georg. A alma e as formas. Trad. Rainer Patriota. Belo Horizonte: Autêntica, 2015 .

NUNES, Benedito. Oswald canibal. São Paulo: Perspectiva, 1979. (Coleção Elos)

PERRONE-MOISÉS, Leyla. Mutações da literatura no século XXI. São Paulo: Companhia das Letras, 2016.

ROCHA, João Cezar de Castro. Machado de Assis: por uma poética da emulação. Rio de Janeiro, Civilização Brasileira, 2013.

ROCHA, João Cezar de Castro. Uma poética da emulação: uma leitura de Machado de Assis. In: JOBIM, José Luís; MELLO, Maria Elizabeth Chaves de; KLEIMAN, Olinda (Orgs.). O diálogo Europa-Brasil na obra de Machado de Assis. Niterói: Eduff/Faperj/ Sorbonne Nouvelle, 2015, pp. 23-48.

RIBEIRO, Roberto Carlos. Escrita do eu: crítica e ficção em Silviano Santiago. Darandina Revista Eletrônica, v. 2, n. 2, 2010, [s.p.]. Disponível em: <http://www.uff.br/ darandina/files/2010/o2/artigo14a.pdf>. Acesso em: 30 mar. 2018.

RUFFINELLI, Jorge; ROCHA, João Cezar de Castro (Orgs.). Antropofagia hoje? Oswald de Andrade em cena. São Paulo: É Realizações Editora, 2011.

SANTIAGO, Silviano. Em liberdade. Rio de Janeiro: Paz e Terra, 1981.

SANTIAGO, Silviano. A política através da palavra escrita. [Entrevista a Lucia Helena]. Brasil/Brazil-Revista de literatura brasileira, Porto Alegre, n. 7, 1992, pp. 83-96.

SANTIAGO, Silviano. Viagem ao México. Rio de Janeiro: Rocco, 1995.

SANTIAGO, Silviano. Uma literatura nos trópicos. Ensaios sobre dependência cultural. 2. ed. Rio de Janeiro: Rocco, 2000.

SANTIAGO, Silviano. Heranças. Rio de Janeiro: Rocco, 20o8a.

SANTIAGO, Silviano. O começo do fim. Gragoatá, n. 24, 1osem. 2008b, pp. 13-30.

SANTIAGO, Silviano. [Entrevista a Mauricio Meireles]. Folha de São Paulo, Ilustrada, 13 dez. 2016a, pp. 161-178. 
Remate de Males, Campinas-SP, v. 38, n. 1, pp. 398-413, jan./jun. 2018 - 413

SANTIAGO, Silviano. Machado. São Paulo: Companhia das Letras, 2016b.

SARDUY, Severo. O barroco e o neobarroco. In: América latina em sua literatura. São Paulo: Perspectiva, 1979.

SCHOLLHAMMER, Karl Erik. Além do visível o olhar da literatura. 2. ed. Rio de Janeiro: 7Letras, 2016.

SILVA, Vivien Gonzaga e. O ensaio como zona de fronteira: o pensamento crítico de Silviano Santiago e Michel de Montaigne. Itinerários-Araraquara, v. 22, 2004, pp. 91-102. Disponível em: <https://periodicos.fclar.unesp.br/itinerarios>. Acesso em: 30 mar. 2018.

VELOSO, Caetano. Verdade tropical. São Paulo: Companhia das Letras, 1997. 